CRUDE CHRONILLES 



\section{Srude Chronieles}

Indigenous Politics, Multinational Oil, and

Neoliberalism in Ecuador Suzana Sawyer

DUKE UNIVERSITY PRESS Durham \& London 2004 
(C) 2004 Duke University Press. All rights reserved Printed in the United States of America on acid-free paper $@$ Designed by Rebecca M. Giménez. Typeset in Adobe Minion by Tseng Information Systems. Library of Congress Cataloging-inPublication Data appear on the last printed page of this book. 
For

Dorothy Anne Sawyer

and

J. Allan Sawyer,

with love 

AMERILAN ENCOUNTERS/

GLOBAL INTERACTIONS

A series edited by Gilbert M. Joseph

and Emily S. Rosenberg

This series is intended to stimulate

critical perspectives and fresh interpretive frameworks for scholarship on the history of the imposing global presence of the United States. Its primary concerns include the deployment and contestation of power, the construction and deconstruction of cultural and political borders, the fluid meanings of intercultural encounters, and the complex interplay between the global and the local. American Encounters seeks to strengthen dialogue and collaboration between historians of U.S. international relations and area studies specialists.

The series encourages scholarship based on multiarchival historical research. At the same time, it supports a recognition of the representational character of all stories about the past and promotes critical inquiry into issues of subjectivity and narrative. In the process, American Encounters strives to understand the context in which meanings related to nations, cultures, and political economy are continually produced, challenged, and reshaped. 
